\title{
Acute and Subchronic Tramadol Toxicity on Brain and Spinal Cord of Male Albino Rats
}

\author{
Hala M Fathy, Heba A.Yassa, Doaa M.G.Almaz', and Rabab A.Mohamed²
}

${ }^{1}$ Department of Forensic Medicine and Clinical Toxicology
${ }^{2}$ Department of Pathology

Faculty of Medicine, Assiut University, Assiut, Egypt.

\begin{abstract}
Tramadol is one of typical centrally acting opioids. It is indicated for management of moderate to severe pain. Now it is considered to be the most widely sold analgesic in the world. Aim: To detect the effect of subchronic administration of tramadol on brain and spinal cord of the experimental animals as histopathologic changes in brain cells. Methods: Sixty adult male albino rats were divided into three equal groups each was 20 rats. Control group, group I that received Tramadol orally at increasing doses 1/10 LD50, 1/5 LD50 and lastly four times the initial dose for the first, second and third months respectively, and Group II that received 1/10 LD50 for one month. All rats were scarified after 24 hours of the last dose at the end of each experimental period under ether anesthesia. Craniotomy and laminectomy were performed for histopathological studies. The presences of number of red neurons which are histological marker of apoptosis were investigated in brain and spinal cord. Results: The number of small sized neurons was greater in group II than in group I. There was statistical difference regarding neuopil density and color staining among three groups. Neuopil was lighter in staining and less dense in groups I and II comparing to control $(\mathrm{p} \leq 0.002$ and $\mathrm{p} \leq 0.001)$ using SPSS program. The highest number of red neurons was found in hippocampal region followed by occipital and frontal regions. The abnormalities regions in the spinal cord tissue were less than those in the brain tissue. Conclusions: chronic use of Tramadol is an important factor responsible for histopathological changes in neurons.
\end{abstract}

\section{Introduction}

$\mathrm{T}$ Tramadol is a centrally acting synthetic analgesic it is a widely prescribed analgesic used in the treatment of moderate to severe pain and as an alternative to opiates (Sansone and Sansone, 2009).

Although tramadol was initially thought to exhibit low abuse potential, Ortho-McNeil, the drug's manufacturer, recently reported a large number of adverse events attributed to tramadol including abuse opioid-dependent patients, allergic reactions, and seizures (Goeringer et al., 1997).

Tramadol overdose has been one of the most common causes of drug poisoning in the recent years especially in male young adults with history of substance abuse (Shadnia et al., 2008).Chronic use of morphine and/or tramadol in increasing doses is found to cause red neuron degeneration in the rat brain, which probably contributes to cerebral dysfunction (Atici et al., 2005).

The alleged usages of tramadol had also contributed greatly to its popularity and massive use especially in youth as a remedy for premature ejaculatory function and for extended orgasm and increase sexual pleasure as promoted through many online drug stores and media (Fawzi , 2011).

The aim of this study is to detect the effect of acute and subchronic administration of tramadol on brain and spinal cord of the experimental animals.

\section{Materials and Methods}

\section{Drugs and Chemicals}

Tramadol hydrochloride (TH): Commercially available Tramal ${ }^{\circledR}$ ampoules. Each ampoule contains 100 $\mathrm{mg} / \mathrm{ml}$. tramadol hydrochloride (tramal, manufactured by Mina Pharm, Egypt), Ethyl alcohol $100 \%$, Nacl saline $0.9 \%$, ether anesthesia, Xylene, Parrfin wax, and Haematoxyline and Eosine stain.

\section{Methods}

Sixty adult male albino rats were used, obtained from the animal house, Faculty of Medicine, Assiut University. Their weights were between 160-180 grams at the beginning of the study. According to the 
ethics of the experimentation on animals, rats were housed in groups in clean capacious macrolane cages (5 per cage) under standard laboratory conditions including good aerated room with suitable temperature, maintained at good light, with alternating 12 hours light and dark cycle. Standard rats' food and water were available.

The rats were randomly divided into three groups as follow:

- Control Group: (20 male albino rats): was divided into two subgroups, (a) each animal received $1 \mathrm{ml}$ of normal saline $0.9 \%$ orally by gavages for 90 days and (b) in which animals received saline for 4 weeks daily by gastric gavage.

- Group I: (20 male albino rats) received graduated increasing dose firstly received $1 / 10$ LD50 $(30 \mathrm{mg} / \mathrm{kg} /$ day) for one month, then increasing to be duplicated each animal received $60 \mathrm{mg} / \mathrm{kg} /$ day $(1 / 5 \mathrm{th}$ $\mathrm{LD}_{50}$ ) of $\mathrm{TH}$ orally by gavage for another one month and lastly in the third month received four times the initial dose $(120 \mathrm{mg} / \mathrm{kg} /$ day $)$ (Matthiesen et al., 1998). This group was given tramadol orally by gavage daily for 3 months. Their weight was observed once a week.

- Group II: (20 male albino rats) received $30 \mathrm{mg} / \mathrm{kg} /$ day (1/10th $\mathrm{LD}_{50}$ ) of $\mathrm{TH}$ orally by gavages daily for one month (Matthiesen et al., 1998).

The animals were observed during all the experimental period for clinical signs of toxicity [weight gain (weighing every week)]. Statistical analysis was done using SPSS Program (Statistical Package for the Social Science).

At the end of each experimental period and under ether anesthesia all animals were sacrificed after 24 hours of the last dose. Dead animals in each group were dissected, craniotomy and laminectomy were performed and intact brains and spinal cords were dissected and examined for histopathological studies to know the underlying histopathological changes.

\section{Histopathological examination}

The brains were removed and dissected into several regions (cerebral cortex and hippocampus) according to the guidelines of Glowinski and Iversen (1966). Then laminectomy was performed to extract a lumbosacral spinal cord (L1-S3) segment. After cutting all of ventral and dorsal roots, the pia-arachnoid membrane was removed. The spinal cord was cutted into 650-mm-thick transverse slice (Koga et al., 2005) then postfixed in $10 \%$ formalin for 7 days, and then paraffin embedded. Paraffin blocks were sectioned into $4-5 \mu \mathrm{m}$ (micrometer) thick sections. Serial sections of brain were stained with haematoxylin and eosin $(\mathrm{H}$ $\& E$ ) according to Drury and Wallington (1980) to be examined by light microscopy for histopathological changes.

\section{Results}

Tramadol administration for three months to male albino rats (Group I) lead to significant decrease in weight of the experimental animals in comparison to the control group table (1) and figure (1). Table (2) and Figure (2) illustrate the relation between the tramadol administration for one month (Group II) to male albino rats and the decrease in weight. They show significant decrease in the weight of the experimental animals in comparison to the control rats.

\section{Histopathological examination of brains and spinal cords of rats after tramadol administration}

\section{Findings in Brain tissue}

\section{1- Control group (rats taking saline)}

The control group showed no remarkable pathological findings. The cortex showed vast number of neurones and their processes embedded in a mass of support cells (the neuroglia) (Table 3 and figure 3 ).

\section{2- Group I: (gradually increasing doses of tramadol for $\mathbf{3}$ months) and Group II (tramadol for one month)}

Dark neurons were detected at higher density in these groups of animals comparing with the control group (Table-3, figure 3 and figure 5). There were distortion in shape of neurons, small sized neurons, abnormalities in neuroglia shape and distribution; neuropil (defined as any area in the nervous system composed of mostly unmyelinated axons, dendrites and glial cell processes that forms a synaptically dense region containing a relatively low number of cell bodies) staining was found fainter in some animals and less dense in others (Table-4, figure 4 and figure 6).

There was statistical difference between the density of dark neurons of the control group on one side and Group I \& II $(\boldsymbol{P}<\mathbf{0 . 0 0 1})$ using $\mathrm{t}$ - test, but there was no significant difference between Group I and Group II. The highest count of dark neurons was found in the hippocampal region followed by the occipital and the frontal regions as shown in (Table 3 and figure $3,5,6)$.

There was no statistical difference regarding presence of small sized neurons, distorted neurons, neuroglaia abnormal shape, neuroglaia abnormal distribution between the three groups using Chi square test. However there was statistical difference regarding neuropil density and color staining among the three groups. Neuropil was lighter in staining and less dense in group I comparing with group II and the control, (P0.002, $P<0.001)$ using t-test.

\section{Findings in the spinal cord tissue}

The abnormalities found in the spinal cord tissue are much less than those present in the brain tissue. The only change was found in the neuropil. It was fainter in staining and was less dense in group I \& II compared with the control. (Table 7 and figure 7) summarize these findings. 
Table (1): Paired $t$ - test showing the differences in weight of male albino rats given tramadol for three months (Group I) and controls.

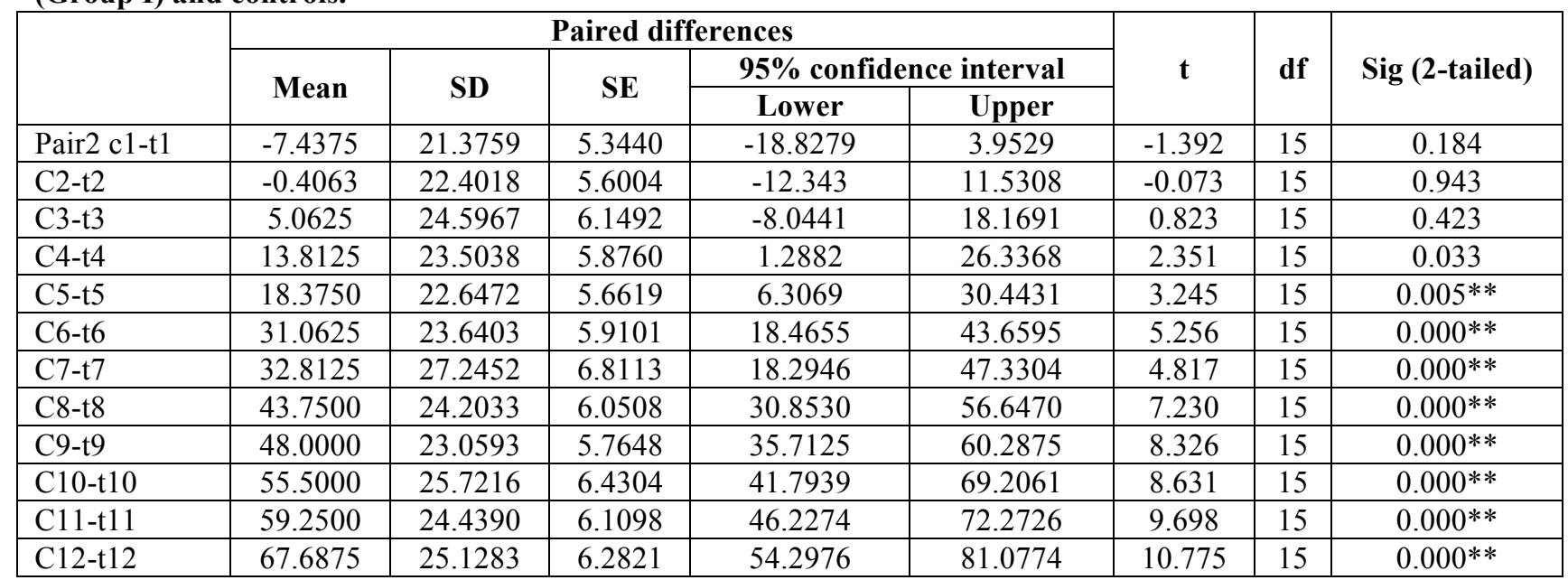

$* P<0.05$ significant.

$* * P<0.01$ highly significant

$D f=$ Degree of difference

$S D=$ Standard Deviation

$S E=$ Standard Error

$c-t=$ control group - treated group

$d f=$ degree of differences

$t=$ value of $t$-test

1,2,3,4 ........12 number of weeks till end of administration periods 3 months $=12$ weeks

Table (2): Paired - $t$ test showing the differences between weights of rats takes tramadol for one month (Group II) and control.

\begin{tabular}{|c|c|c|c|c|c|c|c|c|}
\hline & \multicolumn{5}{|c|}{ Paired differences } & \multirow{3}{*}{$\mathbf{t}$} & \multirow{3}{*}{ df } & \multirow{3}{*}{ Sig (2-tailed) } \\
\hline & \multirow{2}{*}{ Mean } & \multirow{2}{*}{ SD } & \multirow{2}{*}{ SE } & \multicolumn{2}{|c|}{ 95\% confidence interval } & & & \\
\hline & & & & Lower & Upper & & & \\
\hline Pair 1 Begin- begin & -0.926 & 2.58 & 0.6911 & 2.421 & 0.564 & 1.344 & 13 & 0.202 \\
\hline Pair2 c1-t1 & 34.71 & 38.20 & 10.21 & 12.65 & 56.77 & 3.400 & 13 & $0.005^{*}$ \\
\hline $\mathrm{C} 2-\mathrm{t} 2$ & 37.28 & 37.99 & 20.15 & 15.348 & 59.223 & 3.672 & 13 & $0.003 * *$ \\
\hline $\mathrm{C} 3-\mathrm{t} 3$ & 37.71 & 43.8 & 11.71 & 12.418 & 63.01 & 3.221 & 13 & 0.007 \\
\hline C4-t4 & -97.71 & 544.84 & 145.61 & -.412 .30 & 216.87 & -0.671 & 13 & 0.514 \\
\hline
\end{tabular}

$* P<0.05$ significant.

$* * P<0.01$ highly significant

$D f=$ Degree of difference

$S D=$ Standard Deviation

$S E=$ Standard Error

$c-t=$ control group - treated group

$d f=$ degree of differences

$t=$ value of $t$-test

1,2,3,4 ........12 number of weeks till end of administration periods 3 months $=12$ weeks

Table (3): $t$ - test statistical analysis for average density of dark neurons counted / 10 HPFs in the different regions of the brain.

\begin{tabular}{|l|c|c|c|c|}
\hline & Control & Group I & Group II & P value \\
\hline DNs-Frontal & 5 & 13.8 & 11.4 & 7.8 \\
\hline DNs-parietal & 5.1 & 9.5 & 11 & \multirow{2}{*}{ P $<0.001 * *$} \\
\hline DNs-Temporal & 5 & 11.5 & 8.7 & \\
\hline DNs-Entorhinal & 4.5 & 10.4 & 1 & \\
\hline DNs-pyriform & 4.9 & 9.4 & 10.7 & \\
\hline DNs-occipital & 4.8 & 17.65 & 16.9 & \\
\hline DNs-Hippocampal & 4.25 & 19.2 & & \\
\end{tabular}

$* P<0.05$ significant.

$* * P<0.01$ highly significant

DNs = Dark neurons

$H P F s=H i g h$ power file system 
Table (4): t- test statistical analysis for average distribution of morphological findings in the animal brains of the three groups (Control - Group I - Group II).

\begin{tabular}{|l|c|c|c|c|}
\hline \multicolumn{1}{|c|}{ Morphological changes } & Control & Group I & Group II & P value \\
\hline Small Neurons & 5 & 5 & 8 & 6 \\
\hline Neuron Distortion in shape & 5 & 6 & 3 & \multirow{2}{*}{ P $<0.04 *$} \\
\hline Neuroglaia with abnormal shape & 5 & 6 & 3 & \\
\hline Neuroglaia with abnormal distribution & 3 & 4 & 6 & \\
\hline Neuropil with abnormal density & 3 & 14 & \\
\hline Neuropil with faint color staining & 2 & 12 & 8 & \\
\hline
\end{tabular}

$* P<0.05$ significant.

$* * P<0.01$ highly significant

$D N s=$ Dark neurons

HPFs $=$ High power file system

Group I= received tramadol in graduated dose for three months

Group $I I=$ received tramadol for one month

Table (5): Chi Square statistical analysis for morphological changes in brains of the three groups (Control Group I - Group II).

\begin{tabular}{|c|l|c|c|c|c|c|c|}
\hline \multicolumn{2}{|c|}{ Small sized neurons } & \multicolumn{2}{c|}{ Distorted neurons } & \multicolumn{2}{l|}{ Neuropil abnormal density } & \multicolumn{2}{c|}{ Neuropil abnormal color staining } \\
\hline Chi square value & $\begin{array}{l}P \\
\text { value }\end{array}$ & $\begin{array}{l}\text { Chi square } \\
\text { value }\end{array}$ & $P$ value & Chi square value & $P$ value & Chi square value & $P$ value \\
\hline 3.875 & 0.149 & 1.767 & 0.414 & 12.020 & $\mathbf{0 . 0 0 2} * *$ & 13.36 & $\mathbf{0 . 0 0 1 * *}$ \\
\hline
\end{tabular}

$* P<0.05$ significant.

$* * P<0.01$ highly significant.

Group I: (graduated increasing dose of tramadol for 3 months)

Group II (tramadol for one month)

Significant findings is italic and bold.

Table (6): Chi square statistical analysis for morphological changes in brains of the three groups (control Group I - Group II).

\begin{tabular}{|c|c|c|c|}
\hline Neuroglaia abnormal shape & \multicolumn{2}{c|}{ Neuroglaia abnormal distribution } \\
\hline Chi square value & P value & Chi square value & $P$ value \\
\hline 0.636 & 0.728 & 0.204 & 0.903 \\
\hline
\end{tabular}

$* P<0.05$ significant.

** $P<0.01$ highly significant.

Group I: (graduated increasing dose of tramadol for 3 months)

Group II (tramadol for one month)

Table (7): Average distribution of density of dark neurons counted in spinal cord section and other morphological abnormalities in the spinal cord in the three groups (Control - GI - GII).

\begin{tabular}{|l|c|c|c|}
\hline Finding & Control & Group I & Group II \\
\hline Density of dark neurons & 1 & 2 & 4 \\
\hline Small Neurons & 0 & 0 & 1 \\
\hline Neuron Distortion in shape & 0 & 1 & 0 \\
\hline Neuroglaia with abnormal shape & 1 & 1 & 2 \\
\hline Neuroglaia with abnormal distribution & 0 & 0 & 1 \\
\hline Neuropil with abnormal density & 0 & 5 & \\
\hline Neuropil with abnormal color staining & 0 & 7 & \\
\hline
\end{tabular}

Group I: (graduated increasing dose of tramadol for 3 months)

Group II (tramadol for one month) 


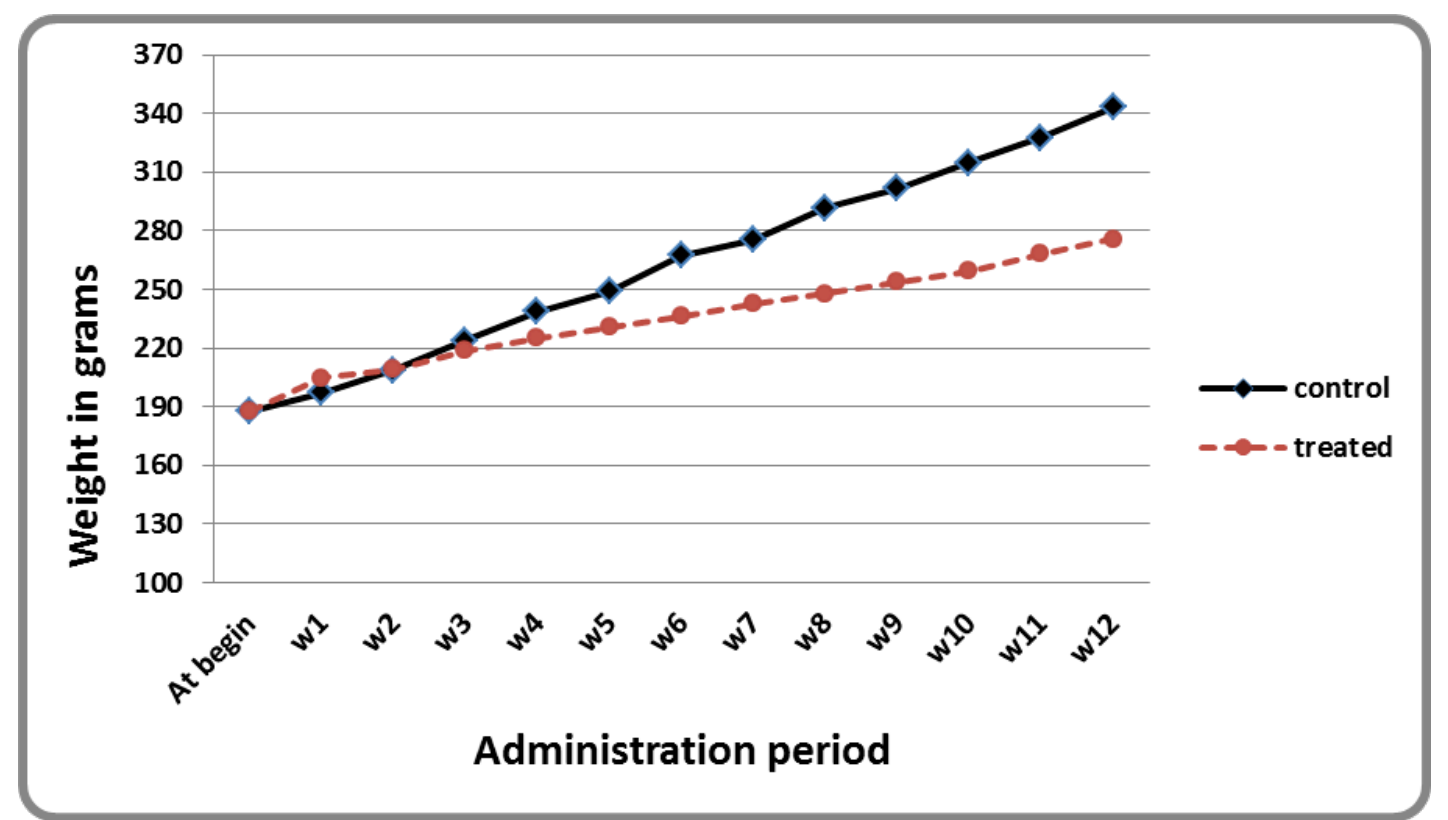

Figure (1): Mean differences between weights of rats treated with tramadol for three months (group I) and control.

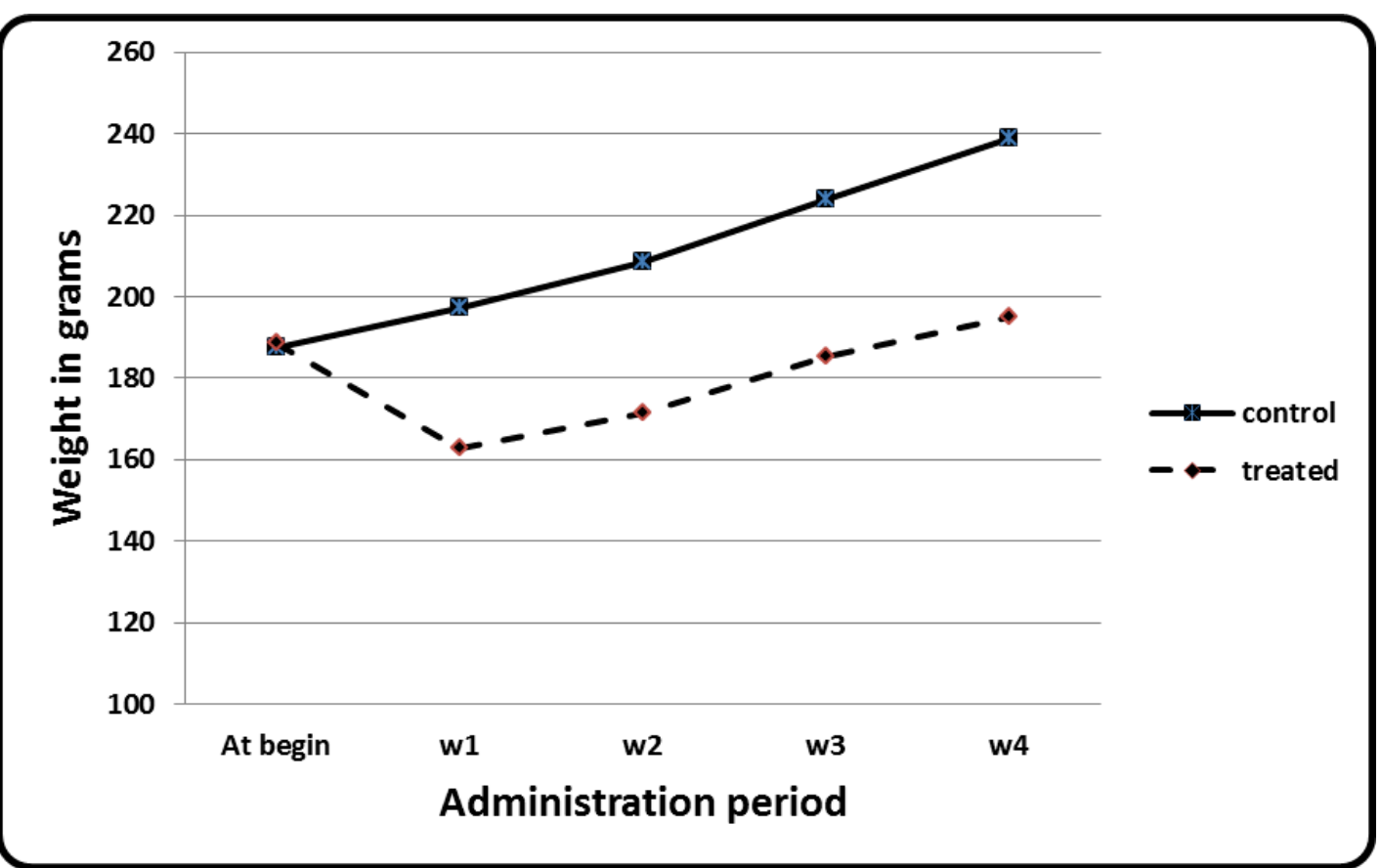

Figure (2): Mean differences between weights of rats treated with tramadol for one month (group II) and control. 


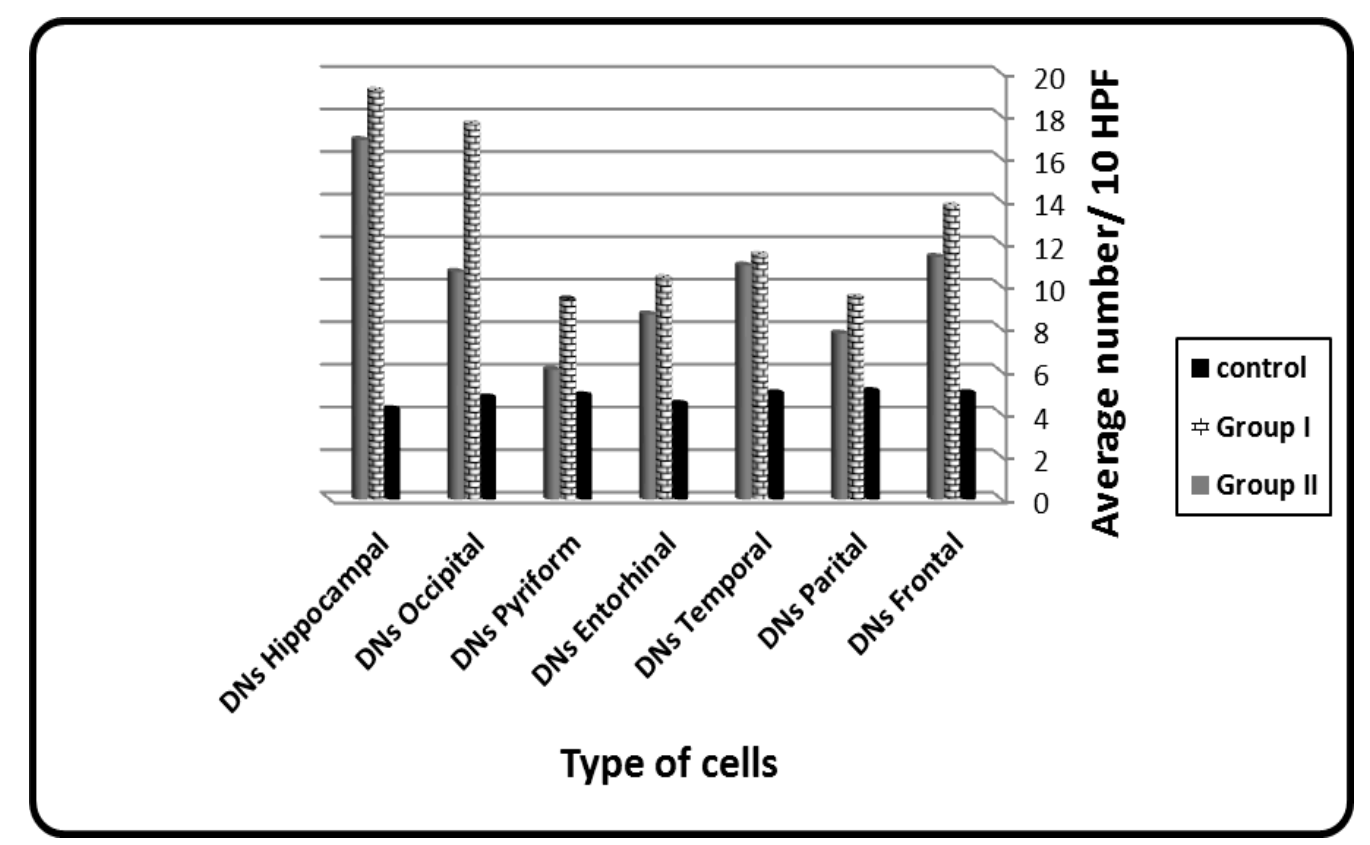

Figure (3): Histogram showing average density of dark neurons counted / 10 HPFs in the different regions of the brain.

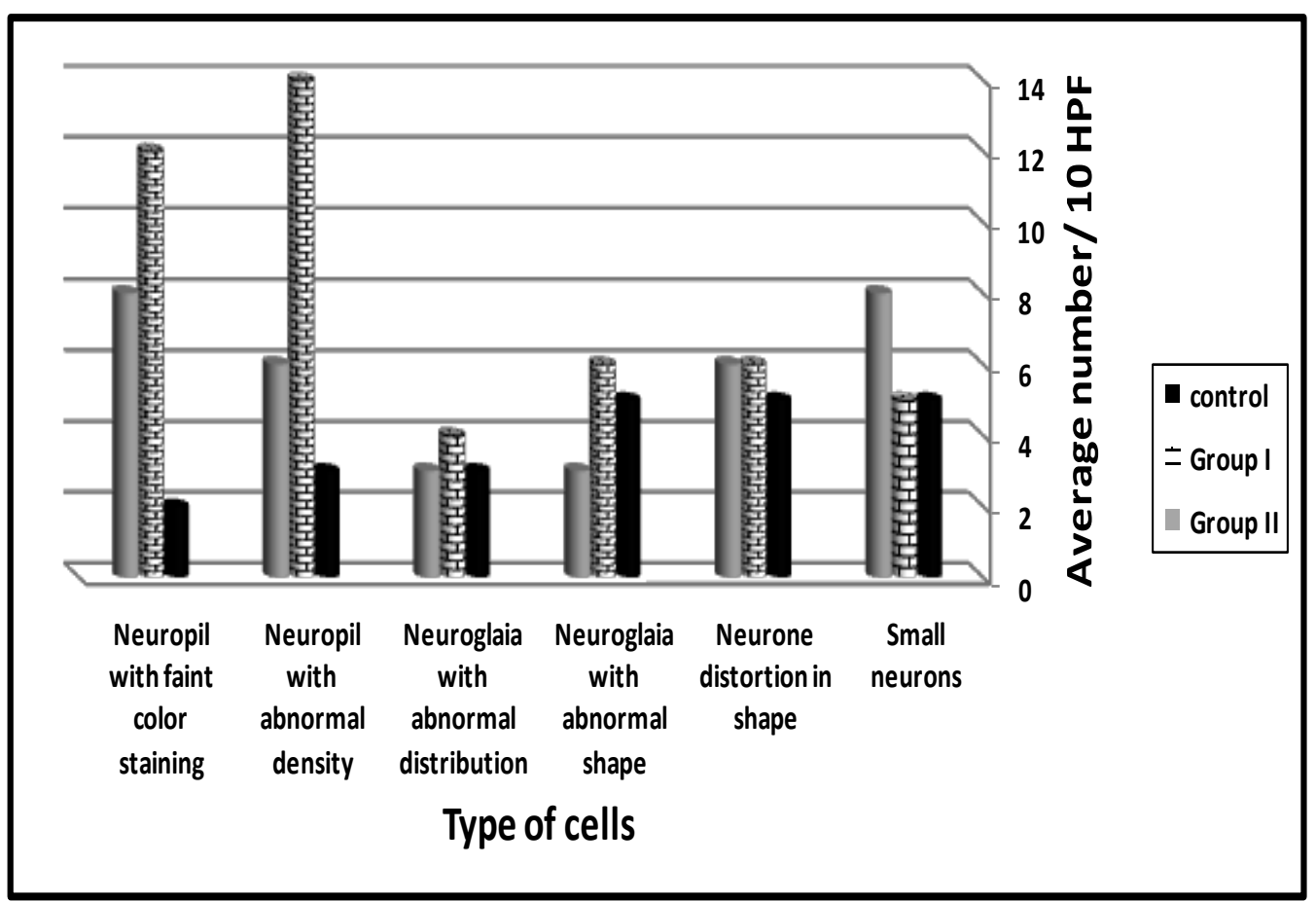

Figure (4): Histogram showing distribution of morphological findings in the animal brains in the three groups. Group I shows significant changes in the neuoropil density and color staining. 


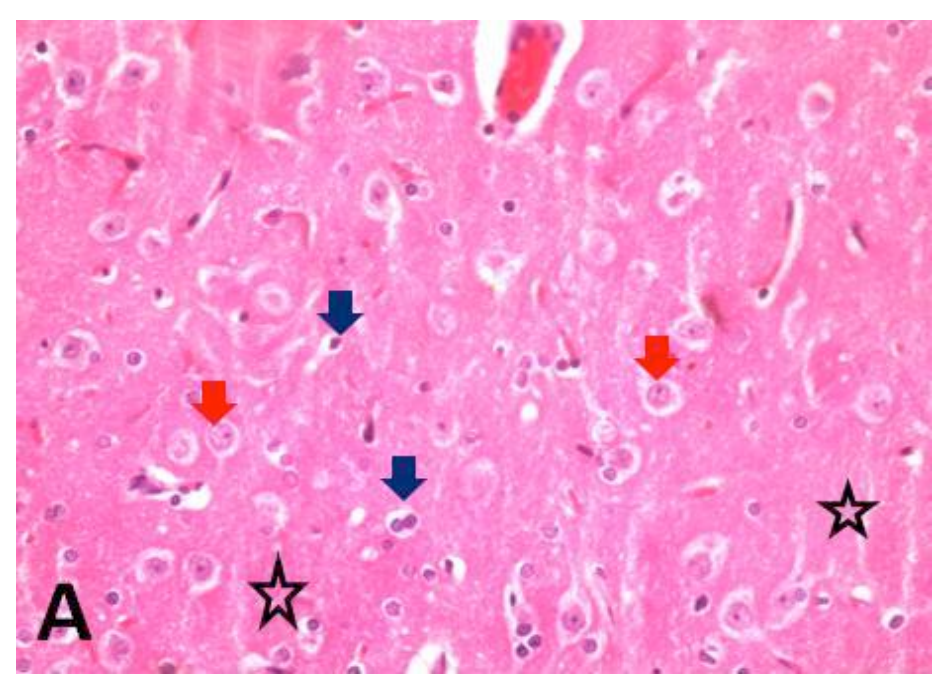

Figure (5A): A photomicrograph of transverse section in the hippocampal region, from control group, the neural cells (red arrows) are well recognized with their large body; big rounded nucleus and small nucleolus (blue arrows) show the astrocytes and oligodendrocytes. The stars are areas of the neuropil $\mathbf{2 0 0 .}$

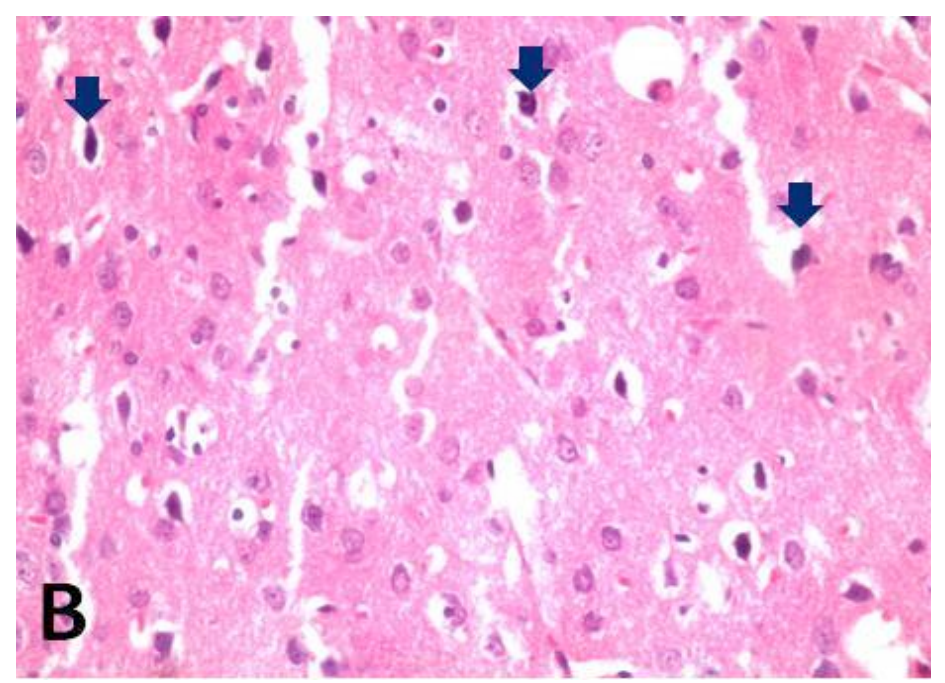

Figure (5B): A photomicrograph of transverse section in the hippocampal region from rat in group I (received graduated dose of tramadol in 3 months) showing the presence of dark neurons (arrows) $\mathbf{2 0 0}$.

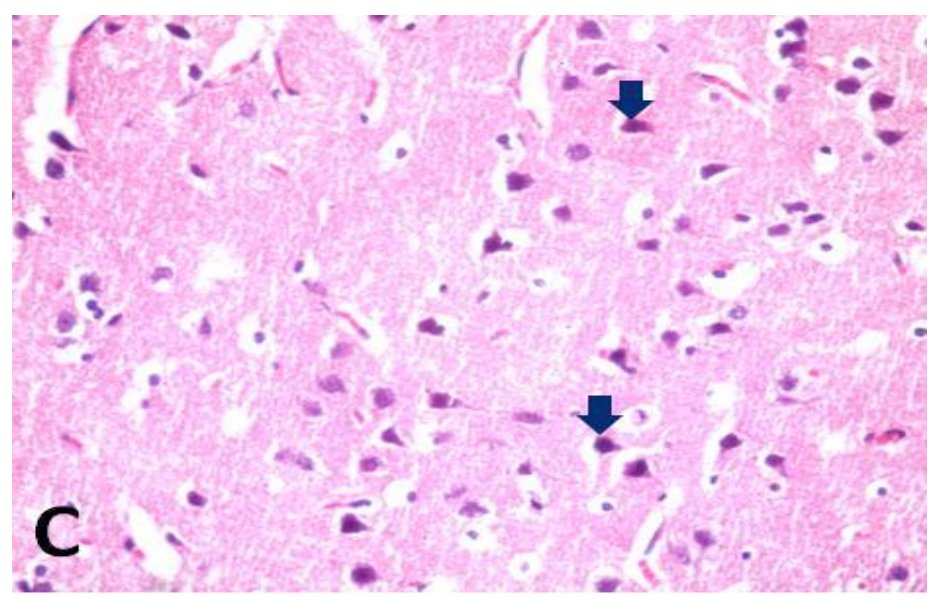

Figure (5 C): A photomicrograph of transverse section in the hippocampal region from rat in group II (received tramadol for one month) showing the presence of dark neurons (arrows) x200. 


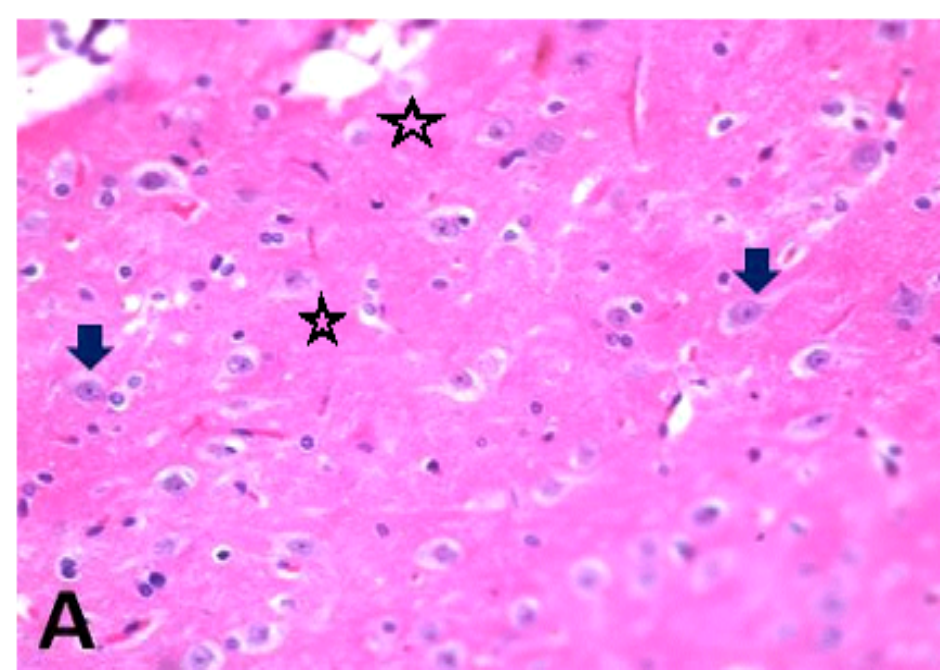

Figure (6A): A photomicrograph of transverse section in the occipital region from control group, the neural cells (arrows) is well recognized with their large body, big rounded nucleus and small nucleolus. The neuropil (stars) appear deeply pink in color. $x 200$.

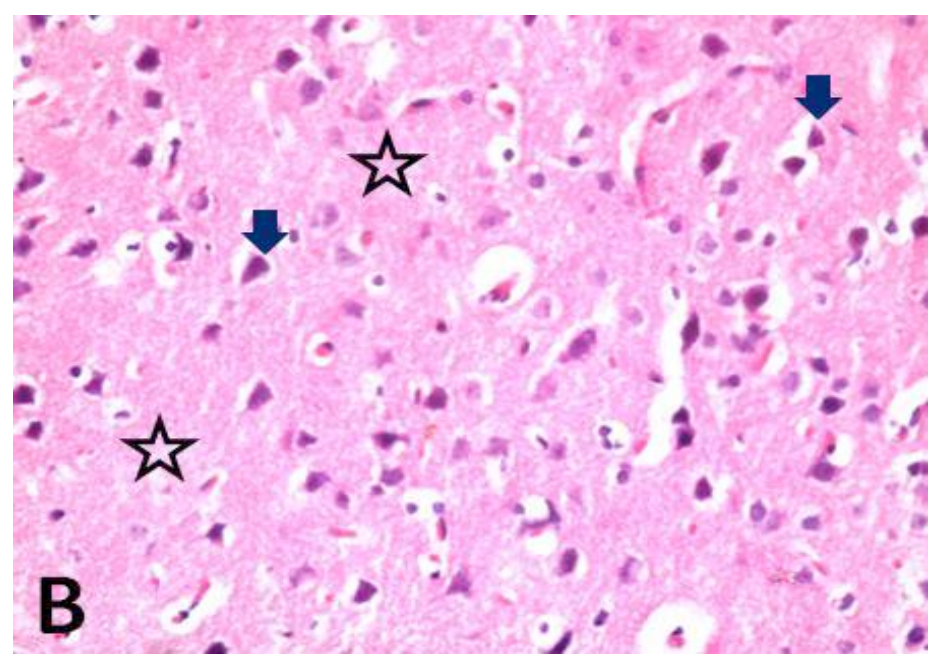

Figure (6B): A photomicrograph of transverse section in the occipital region from rat in group I, received tramadol for three months in graduated dose, showing the presence of dark neurons (arrows) and pale staining of the neuropil (stars) $\mathbf{2 0 0}$.

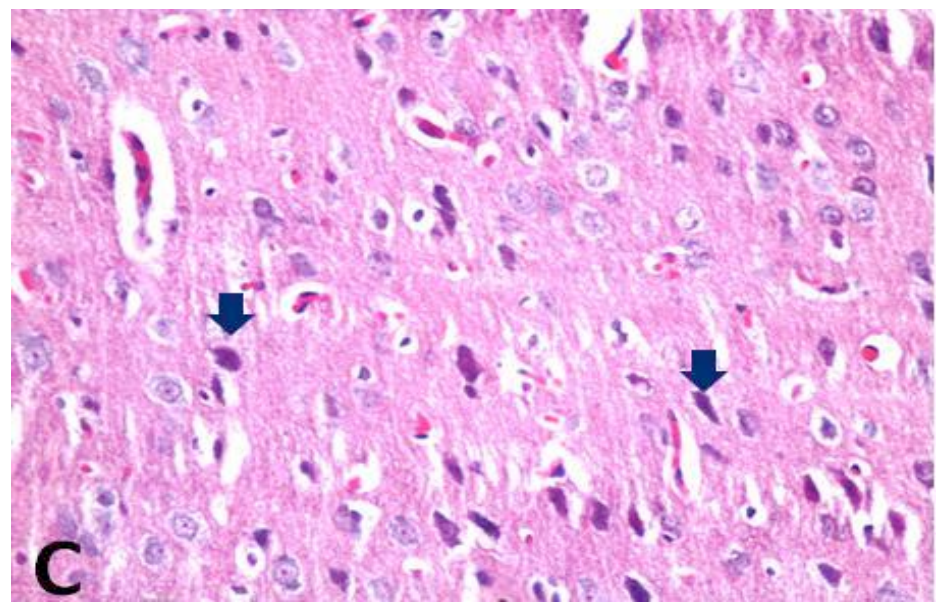

Figure (6C): A photomicrograph of transverse section in the occipital region from rat in group II, received tramadol for one month, showing the presence of dark neurons (arrows) x200. 


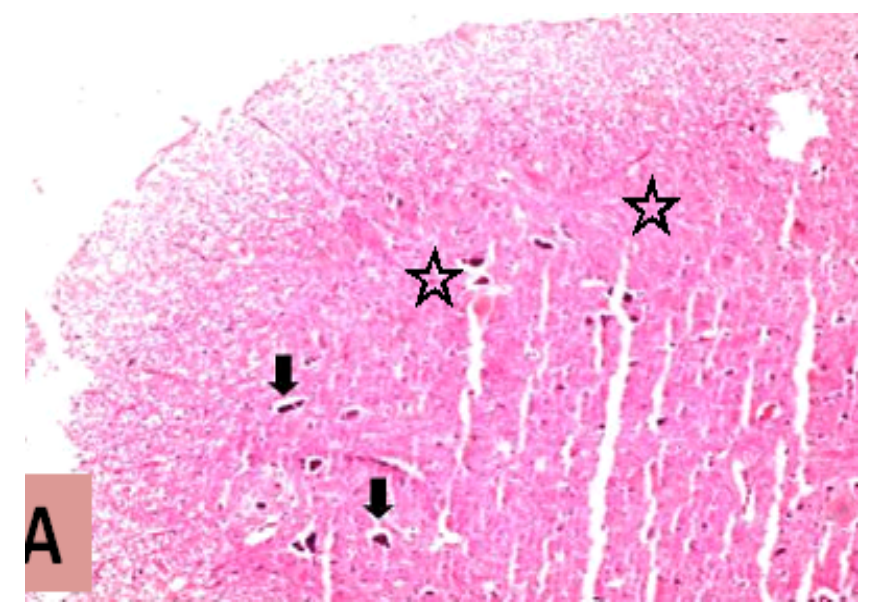

Figure (7A): A photomicrograph of transverse section in the spinal cords from rats in control group $x 200$. The anterior horn cells are well apparent (arrows) and the neuropil of usual density and color (stars)

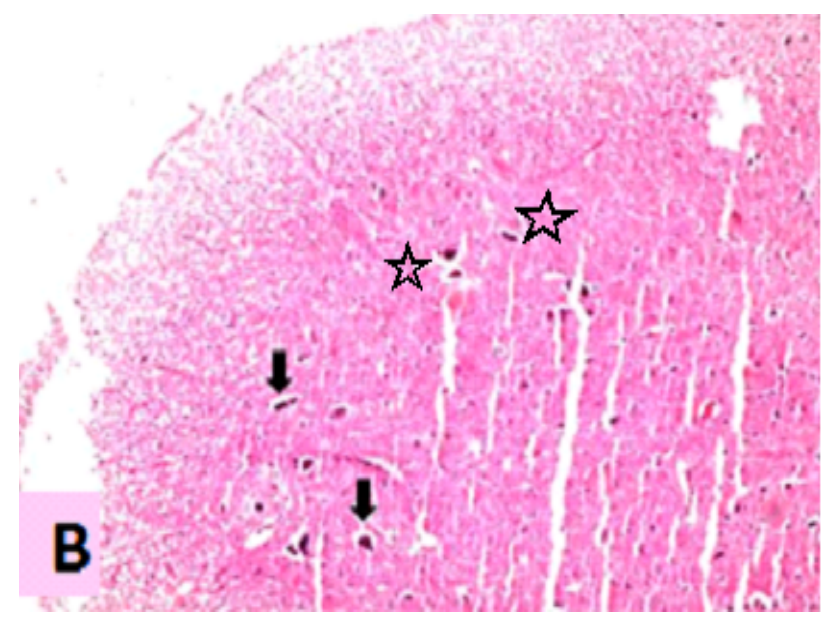

Figure (7 B): A photomicrograph of transverse section in the spinal coed from rat in group I (received tramadol in graduated dose for three months), showing no remarkable pathological changes. The anterior horn cells are well apparent (arrows) and the neuropil of usual density and color (stars) $\mathbf{2 0 0}$.

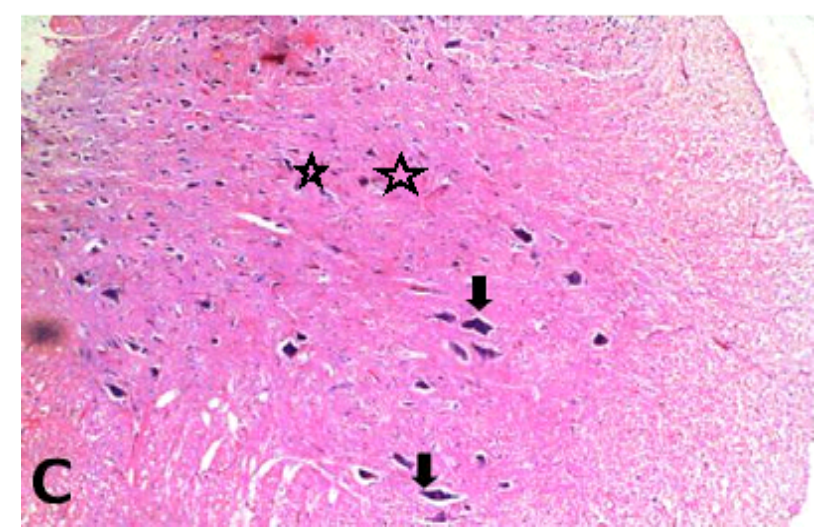

Figure (7 C): A photomicrograph of transverse section in the spinal coed from rat in group II (received tramadol for one month), showing no remarkable pathological changes. The anterior horn cells are well apparent (arrows) and the neuropil of usual density and color (stars) $\mathbf{2 0 0}$.

\section{Discussion}

An increasingly alarming phenomenon of tramadol drug abuse has been demonstrated in the Egyptian community (Fawzi, 2011). Tramadol was approved for marketing as a non controlled analgesic in 1995 under the trade name of Ultram (Marquardt et al., 2005). Recently, tramadol was put in Schedule I in Egypt since September 2009 (www.eda.mohp.gov.eg. 2009), by Egyptian Drug Authority.
In the present study, the effect of long term administration of TH (Tramadol Hydrochloride) on the brain and spinal cord morphology by histopathological investigations were studied in adult male albino rats. The male albino rats were followed up after taking the dose of tramadol and the results were recorded, the rats become hyperactive, and aggressive in the form of biting each other and biting the hands of the worker 
dealing with them, these results are in agreement with Matthiesen et al., (1998). This is related to many factors among which are the serotonin syndrome associated mechanism is the mostly prominent (Fawzi, 2011).

There were significant changes in body weight in comparison with the control group. The results of (www.medsafe.govt.nz.) (2011) and Santos et al., (2001) are in agreement with our results, this may be explained by changes in appetite which is due to tramadol effects.

In the histopathological results, the presence of dark neurons in brain and spinal cord was significantly higher in group I and group II compared with the control group. The exact mechanism for appearance of dark neurons is not yet fully understood. Some studies reported that appearance of dark neurons indicates a chemical cellular injury (ZaaWr et al., 2008).

The significant difference present in group I was the appearance of more faintly stained and less dense neuropil (Fig 6). No study reported similar finding. This may be explained by the effect of tramadol on serotonin receptors. As serotonin has an effect on endothelial cell permeability. Tramadol may affect blood brain barrier microenvironment causing disturbance in fluid effusion and uptake which would result into fluid accumulation and therefore less dense neuropil (Alici et al., 2003). It is unclear however, why this effect was pronounced in group I.

In the present study there were distorted neurons, abnormal density and colour of neutropil in group I in (table 5 and figure 6). The studies reported by Alici et al. (2003) and Khodeary et al., (2010) are in agreement with our results as they concluded that the degenerating red neurons were characterized by retracted brightly eosinophilic cytoplasm, nuclear pyknosis, pale and/or vacuolated neuropil "malacia" surrounding the eosinophilic neurons.

On the other hand, in a neurotoxicity study, tramadol was administered orally to rats using dosages up to $30 \mathrm{mg} / \mathrm{kg}$ /day for one month. Both histopathological and electron microscopy evaluations of different brain regions recognized no treatmentrelated morphological lesions (Matthiesen et al., 1998). These findings disagree completely with the present study.

In a study carried out by Atici et al., (2004), red neurons were found in tramadol groups which received the drug intraperitoneally at doses of 20, 40, and $80 \mathrm{mg} / \mathrm{kg} /$ day in the first, second, and the third 10 days of the study, respectively. This result is in agreement with our result as in (table 4 and fig. 4).

Sastry and Rao, (2000) and Yuan and Yankner, (2000) concluded that the regulation of apoptosis is through the glycoprotein, which is a cell surface receptor that belongs to the tumor necrosis factor and nerve growth factor family. Changes in the glycoprotein increase the expression of Fas and/or promoted synthesis of Bax. Fas and Bax are genes promoted apoptosis. This can occur due to chronic use of tramadol as shown in the present study.
Abnormalities occurred in the spinal cord tissue is much less than those occurring in the brain tissue and have the same mechanisms and explanation of brain neurotoxicity. The present study was the first to show red neuron degeneration in various areas of spinal cord when tramadol were used in increasing doses for a period over 4 to 12 weeks. On the other hand, Matthiessen et al. (1998) using tramadol at a dose of $40 \mathrm{mg} / \mathrm{kg} /$ day for two weeks was not able to prove any neurotoxic effect on the brain, brainstem, or the spinal cord.

\section{Conclusions}

The present study illustrated that tramadol could induce neurotoxic effects on long term use. Toxic possibilities should be taken into consideration when chronic use of tramadol, especially if large doses, are indicated. Public awareness should be initiated to point out the fatalities and uncontrolled moods that are associated with tramadol abuse. Although tramadol is reported to be effective in pain management, its toxic effects should be kept in mind. The chronic use of tramadol is an important factor in the occurrence of histopathological changes related to neurons, which may be the cause of cerebral dysfunction after its prolonged use.

\section{Recommendations}

Tramadol drug screening and estimation should be added to all forms of basic toxicological screening especially to those involved in long term administration as chronic pain treatment.

\section{References}

Alici HA, Ozmen I and Cesur M (2003): Effect of the spinal drug tramadol on the fatty acid compositions of rabbit spinal cord and brain. Biol. Pharm. Bull., 26: 1403-1406.

Atici S, Cinel I, Cinel L, et al., (2005): Liver and kidney toxicity in chronic use of opioids: An experimental long term treatment model. J. Biosci. 30(2): 245-252.

Atici S, Cinel I, and Cinel L (2004): Opioid neurotoxicity: comparison of morphine and tramadol in an experimental rat model. J. Biosci., 30: 245-252.

Drury RA and Wallington EA (1980): Carleton's Histological Techniques.5th ed., Oxford University Press, London, P.P. 241-242.

Fawzi MM (2011): Some medicolegal aspects concerning tramadol abuse: The new Middle East youth plague 2010. An Egyptian overview. Egypt. J. of Foren. Scien. ; Vol. 1 (2): 99-102.

Glowinski J and Iversen LL (1966): Regional studies of catecholamines in the rat brain. J. Neurochem.; 13: 655-669.

Goeringer KE, Logan BK, and Christian GD (1997): Identification of tramadol and its metabolites in blood from drug-related deaths and drug- 
impaired drivers, J. Anal. Toxicol; 21(7): 529-37.

Khodeary M F, Sharaf El-Din A I and El Kholy S M (2010): A Histopathological and immunohistochemical study of adult rats' brain after long-term exposure to amadol (tramadol hydrochloride). Mansoura J. Forensic Med. Clin. Toxicol. Vol. XVIII, (1):1-24.

Koga A, Fujita T, Totoki T. et al., (2005): Tramadol produces outward currents by activating 1opioid receptors in adult rat substantia gelatinosa neurons Briti. J. of Pharmaco.; 45 , 602-607.

Marquardt K, Judith A, Alsop J et al., (2005): Tramadol exposures reported to state wide poison control system.Ann. Pharmacother., 39:1039-1044.

Matthiesen T, Wöhrmann T, Coogan TP et al., (1998) : The experimental toxicology of tramadol: An overview. Toxico. Lett. ; 95: 63-71.

Sansone RA and Sanson LA (2009): Tramadol Seizures, Serotonin Syndrome, and Coadministered Antidepressants. Psych.; 6(4): 17-21.
Santos A, Azevedo EN, Oliveira-Filho RM, et al., (2001): Effects of chronic use of tramadol on pregnant albino rats. Trabalhos Originais 23 (02): 113-117.

Sastry PS and Rao KS (2000): Apoptosis and the nervous system. J.of Neurochemis. ; 74: 1-20.

Shadnia S, Soltaninejad K, Heydari K, et al., (2008): Tramadol intoxication: a review of 114 cases. Hum. Exp. Toxicol.; 27(3):2015.

www.eda.mohp.gov.eg/main.asp (2009): Keeping Medicines Safe: Extended A Further Study of the Regulations Guiding the Approval of Medicines in Emerging Markets (Egypt, Peru, Russia and Thailand), accessed in April 2011.

www.medsafe.govt.nz/profs/./arrowtramadolcap (2011): Data sheet for tramadol. Accessed in April 2011.

Yuan J and Yankner BA (2000): Apoptosis in the nervous system. Nature; 407: 802-809.

ZaaWr S, Kherani S, Roland $\mathrm{N}$ et al., (2008): Pharmacologic analysis of the mechanism of dark neuron production in cerebral cortex , Acta Neuropatho.; 8:1-6.

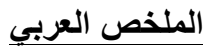

\section{تأثير التسمم الحاد وتحت المزمن للترامادول على المخ والحبل الثوكي في ذكور الفئران}

\author{
هالة محمد فتحي و هبة عطية يسي و دعاء محمد جمعة ألمظ و رباب أحمد أحمد محمد2
}

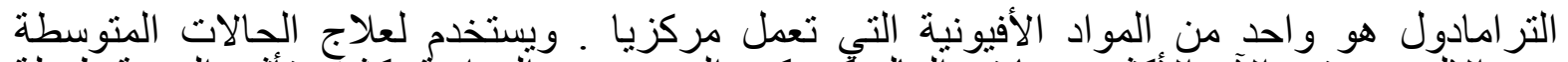

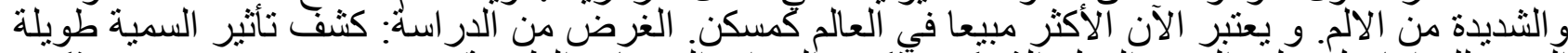

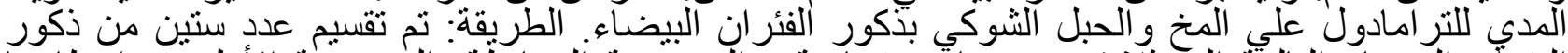

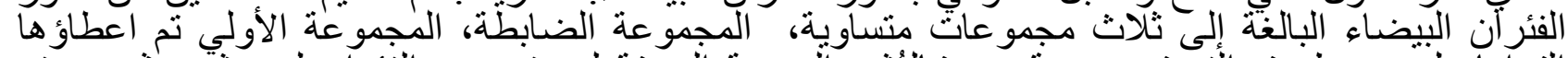

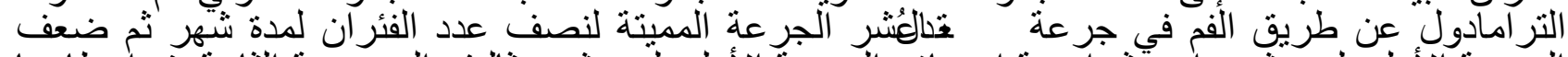

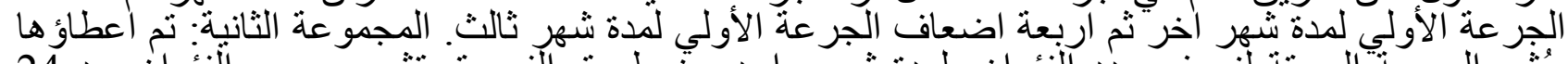

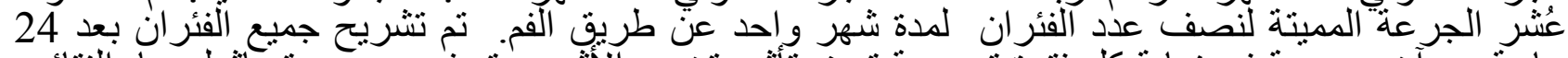

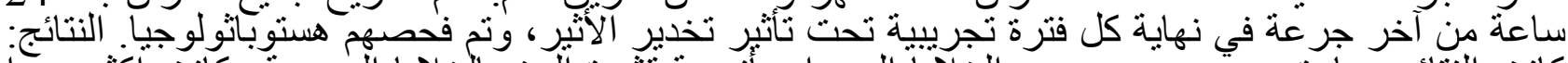

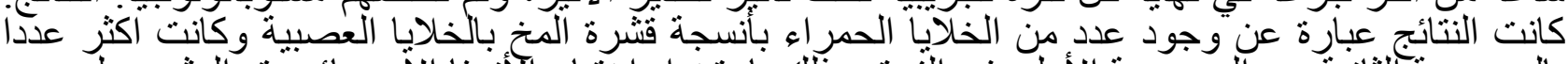

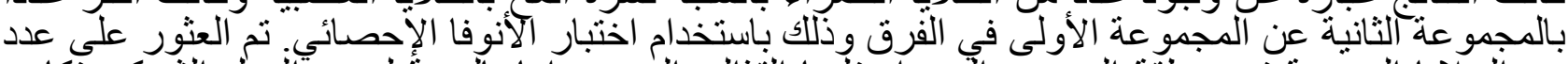

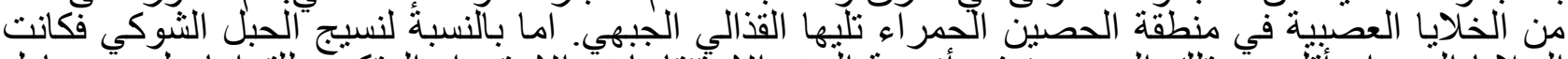

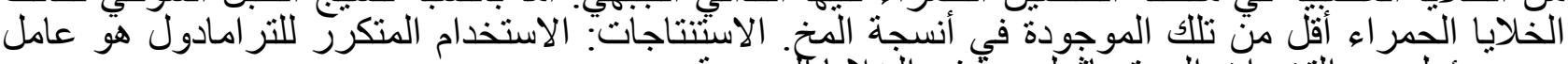

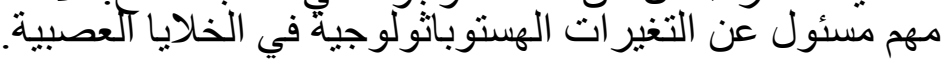

\footnotetext{
1 قسم الطب الثرعي و السموم الإكلينيكية كلية الطب جامعة أسيوط

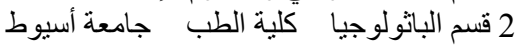

